\title{
Management of severe aortic valve stenosis in the neonate
}

\section{B.J. Mitchell* and S.C. Brown}

*Paediatric Cardiology, Department of Paediatrics and Child Health, University of Pretoria and Steve Biko Academic Hospital, Pretoria, South Africa

\# Paediatric Cardiology, University of the Free State and Universitas Hospital, Bloemfontein, South Africa

Address for correspondence:

B.J. Mitchell

Paediatric Cardiology

Department of Paediatrics and Child Health

University of Pretoria and Steve Biko Academic Hospital

Level D3,

Malherbe Street,

Capital Park,

Pretoria

0002

South Africa

Email:

drlindymitchell@gmail.com

\section{INTRODUCTION}

Severe or critical aortic stenosis (AS) in the neonate represents a cardiac emergency. Unless the diagnosis is made in utero or at delivery, the baby may be discharged home presenting later in extremis when the ductus arteriosus (DA) closes. Management of severe AS is aimed at quickly, safely and adequately reducing the severity of the left ventricular outflow tract obstruction (LVOTO) whilst maintaining the greatest degree of aortic valve integrity and left ventricular function.

\section{BACKGROUND}

Congenital AS comprises $5 \%$ of congenital heart defects, with incidences ranging from 0.04 to 0.38 per 1000 live births..$^{(1,2)}$ There is a clear male predominance with a male to female ratio of $4: 1$. (3) $^{(3)}$ The transmission risk is greater if the affected parent is the mother (recurrence risk $\sim 3 \%$ and $\sim 15 \%$ in children of an affected father or mother respectively). This defect occurs sporadically in most cases. There is an association with Turner Syndrome (45XO) and rarely in William Syndrome $(7 \mathrm{q} / \mathrm{l}$ del). Autosomal dominant inheritance may be associated with mutations in the NOTCHI gene. ${ }^{(4)}$

\section{ABSTRACT}

Aortic valve stenosis (AS) causing obstruction to the left ventricular outflow, and hence reduction of the cardiac output, remains a therapeutic challenge for paediatric cardiologists and cardiothoracic surgeons.

Infants that present at birth may have very dysplastic valves with severe or critical AS and are typically the most difficult to treat. This article therefore focuses on the management of severe AS in the neonate. This article also revises the embryology of the semi-lunar valves, as the morphology of the aortic valve often dictates the treatment pathway. SAHeart 20 | 4; | |:4- | |

AS may occur in isolation, or in association with other congenital cardiac defects. These include other left heart obstructive lesions in Shone association and the hypoplastic left heart syndrome (HLHS) as well as septal defects. It may also occur with extra-cardiac malformations of the renal, gastrointestinal and central nervous systems. ${ }^{(5)}$ The LVOTO is mainly at the level of the annulus (70\%) but may also occur at sub-valvar or supra-valvar levels.

\section{EMBRYOLOGY OF THE SEMI-LUNAR VALVES}

The semi-lunar valves develop from the fourth week of gestation. Neural crest cells from the fourth and sixth pharyngeal arches migrate into the truncus arteriosus and conus cordis and transform into mesenchymal tissue that proliferates to form 2 truncoconal cushions. These 2 endocardial cushions or ridges appear opposite each other in the upper part of the truncus arteriosus, in the dextro-superior and sinistro-inferior positions, and fuse to form the truncal septum. Simultaneously, another 2 intercalated endocardial cushions form, each at $90^{\circ}$ from the first 2 (Figure I). Further cavitation of the ridges (Figure 2) form the 3 triangular-shaped leaflets in each outflow tract: the truncal septum differentiates to form the left and right aortic valve cusps and 2 of the leaflets of the pulmonary valve, and the additional 2 endocardial cushions also evolve, with the right cushion forming the posterior aortic valve cusp, and the left the anterior pulmonary valve leaflet. This occurs during the anti-clockwise rotation and caudal shifting of the conotruncus. The formed semi-lunar valves are thus usually trileaflet with the pulmonary valve's cusps orientated left, right, and anterior and the aortic valve's cusps left, right and posterior. The endocardial 
cushions also transform histologically from a primitive myosin-heavy chain to an alpha-smooth muscle actin phenotype: the mature semi-lunar valve leaflets, which are thinner and more pliable.

Many of the pathways involved in the formation of the semi-lunar valves, especially the role of mesenchymal transformation, are still being explored. Correct valve formation requires proliferation of endocardial cushion tissue, yet this must also be limited to ensure that the cushions can be remodelled to form thin cusps. Congenital abnormalities of the aortic valve such as bicuspid, unicuspid and dysplastic valves are thus thought to be the result of failure of the truncoconal neural crest tissue migration, of incorrect fusion

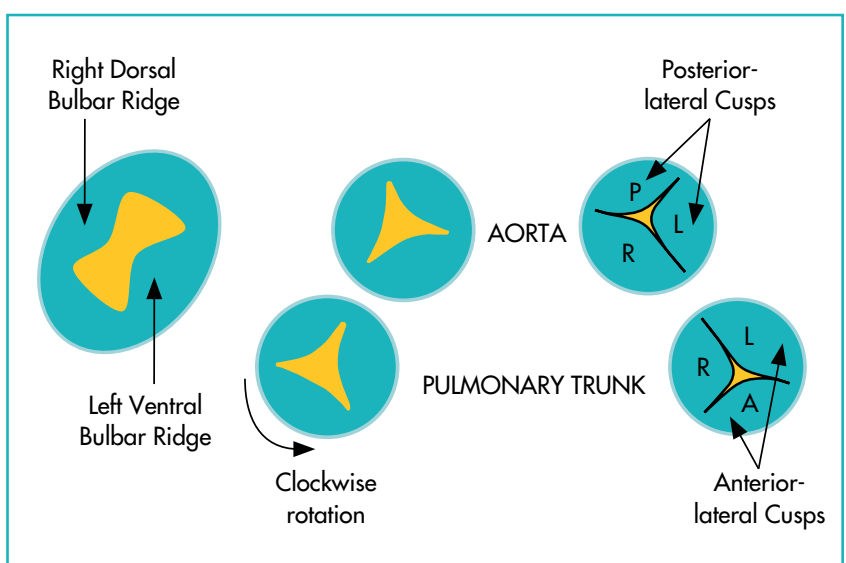

FIGURE I: Embryology of the Semi-lunar valves*

$P=$ Posterior, $A=$ Anterior,$L=L$ eft,$R=$ Right.

* Adapted from http://embryology.med.unsw.edu.au/embryology/indexphptitle= File:Semilunar_Valves.jpg

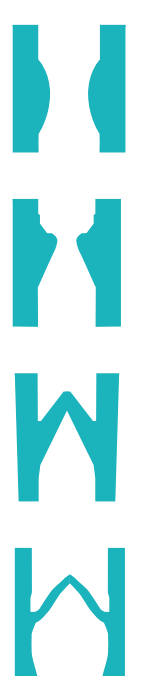

FIGURE 2: Embryology of the Semi-lunar cusps*

* Adapted from http://embryology.med.unsw.edu.au/embryology/indexphptitle= File:Semilunar_Cusps.jpg and/or of incomplete transformation and differentiation of the endocardial cushions. ${ }^{(6,7)}$

\section{PATHOLOGY}

Aortic valves may be morphologically unicuspid (functionally or true), bicuspid (functionally or true), tricuspid (normal) (Figure 3) or rarely quadricuspid. ${ }^{(8)}$

Bicuspid aortic valves (BAV) are common and occur in $0.5-2 \%$ of the population with a 2:I male predominance.(9) The incidence may be as high as 10\% in some families. An exact inheritance pattern has yet to be determined. Currently, it is thought that bicuspid valves are due to the interaction of multiple genes causing abnormal root structure. ${ }^{(10)}$ BAV may occur in isolation or in association with patent ductus arteriosus (PDA), coarctation of the aorta, Williams syndrome (rare) and Turner syndrome. Animal studies have demonstrated a complex interaction between intracellular pathways and individual stem cells rather than just faulty fusion

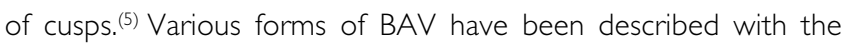
anterior-posterior formation being the most common. ${ }^{(11,12)}$ BAV can develop stenosis and/or incompetence, as well as ascending aorta aneurysms and dissections. ${ }^{(13)}$ Only a quarter of patients will have normal valve function and will require no intervention. ${ }^{(14,15)}$

Unicuspid aortic valves (UAV) are less common and occur in only approximately I of 10000 population. ${ }^{(16)}$ They are associated with significant aortic stenosis. An estimated $50 \%$ of individuals with

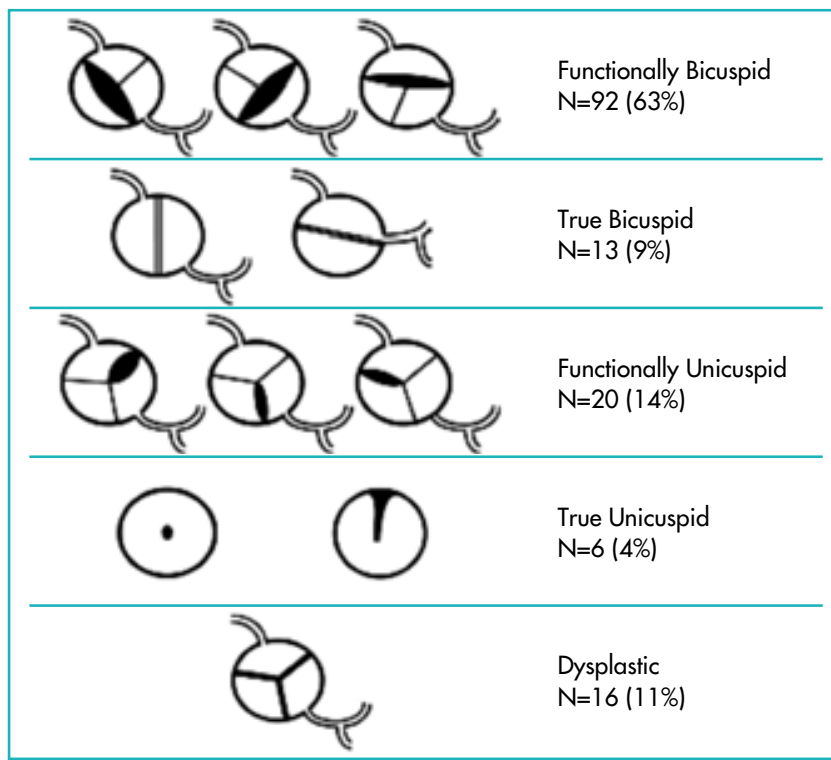

FIGURE 3: Aortic valve variations of morphology as seen in congenital aortic valve stenosis. ${ }^{(8)}$

* Reproduced with permission from Maskatia, et al. Catheter Cardiovasc Interv. 2013; 81:90-95. Wiley 
UAV also have dilation of the ascending aorta. ${ }^{(17)}$ All valves have a single posterior commissural attachment. The free edge of the valve extends from the single commissure without further connection to the aorta.

Quadricuspid aortic valves (QAV) are rare, occurring in only 1-10 patients per 100000 population, with a slight male predominance. ${ }^{(18)}$ This condition was first described by Balington in 1862 and can affect both the pulmonary and aortic valves in a $10: 1$ ratio. ${ }^{(19)}$ Unlike BAV, aortic stenosis is rare. Significant aortic valve incompetence, secondary to a central malcoaptation of the 4 valve leaflets, is commonly observed in QAV.

In the severely dysplastic valve, no normal valve leaflets or anatomy may be distinguishable. Balloon dilation of the aortic valve in this situation, even with a high-pressure, non-compliant balloon, is seldom successful. The valve tissue recoils back to its original position once the balloon is deflated. Open surgical valvotomy with debulking of the leaflets has a far better outcome for this subset of patients. ${ }^{(20,35)}$

\section{MANAGEMENT}

The aim of all AS treatment is to preserve the function of the aortic valve and the left ventricle for as long as possible.

\section{Medical management}

Neonates with severe or critical AS have decreased cardiac output and need urgent haemodynamic support. Resuscitation with fluids and a continuous infusion of alprostadil at a dose of $0.01-0.1 \mathrm{mcg} /$ $\mathrm{kg} / \mathrm{min} \mathrm{IVI}$ must be started without delay. Alprostadil produces vasodilation of the DA smooth muscle and increases cardiac output. Opening and maintaining the patency of the DA will ensure adequate systemic blood flow and perfusion of the vital organs. The infant should be monitored for side-effects, specifically apnoea episodes (12\%). Apnoea is seen most often in neonates with a low birth weight $<2 \mathrm{~kg}$, at higher dosages and usually appears during the first hour of administration. Other adverse effects include: fever (14\%), bradycardia (7\%), hypotension (4\%), seizures (4\%), tachycardia (3\%), diarrhoea (2\%) and sepsis (2\%). Hypokalemia and cardiac arrest occur in $<1 \%$ of patients. ${ }^{(21)}$

Infants with dyspnoea, tachypnoea and increased work of breath ing may have pulmonary oedema secondary to raised left ventricle end-diastolic and left atrial pressures, and may need respiratory support with intubation and positive pressure ventilation. Loop diuretics such as furosemide may be given intravenously in small doses. ${ }^{(20)}$
In neonates with severe AS with low cardiac output and decreased LV function, inotropic support in the form of continuous infusions of dopamine or dobutamine is indicated. Drugs that cause significant vasodilation should be avoided as they may cause hypotension, especially in the low birth weight infant with a small aortic valve area.

Once stabilised, the infant should be referred for urgent intervention to reduce the severity of the LVOTO.

\section{Interventional management}

The stenosis of the aortic valve may be addressed by either balloon valvuloplasty (BV) or surgical valvotomy (SV). In recent years a third alternative, hybrid intervention, has emerged as a palliative measure for infants with borderline hypoplastic left heart dimensions. This entails balloon atrial septostomy with stenting of the PDA by the paediatric cardiologist with pulmonary artery banding by the cardiothoracic surgeon.

The choice of treatment should be guided by evidence-based reviews; local experience and skills. It is usually dictated by the morphology of the aortic valve, the size and function of the left heart, the presence of associated defects and the overall condition and weight of the neonate. The key issue is to decide whether the left heart structures are adequate to sustain the systemic circulation, i.e. a biventricular repair, ${ }^{(22)}$ and if so, what intervention will be the most beneficial for the individual neonate. ${ }^{(23,24)}$ The pros and cons of each intervention have been the subject of many publications. $^{(25,26,27,28,29,30)}$

Many studies have been published comparing the results of SV vs. BV for severe congenital AS. Outcomes such as longterm survival, incidence of aortic valve re-stenosis, residual stenosis or insufficiency (or both), freedom from re-operation and death or need for transplantation have been compared. ${ }^{(31)}$

Brown, et al. were in favour of SV as the primary management for severe AS (although they excluded infants $<2$ months' age and thus arguably the worst morphology as these all underwent open SV (Table 1). ${ }^{(20)}$ There was no significant difference in the characteristics of the 2 groups as regards age, body surface area, valve anatomy and gradient. They demonstrated that gradient reduction, aortic incompetence (Al), and the need for re-intervention were worse for BV. Kaplan-Meier analysis at 10 years of SV vs. BV showed freedom from re-intervention as $72 \%$ vs. $53 \%$ and freedom from AVR $80 \%$ vs. 75\%. They concluded that BV has less reduction in gradient, more residual $\mathrm{Al}$, and a shorter interval between subsequent re-interventions than SV. Further they 
showed that SV is safe and effective with low residual amounts of $A S$ and $A l$, allowing $A V R$ to be delayed until the child is older. A summary of several studies of BV and SV are shown in Tables 2 and 3. ${ }^{(20)}$

\section{SURGICAL VALVOTOMY (SV)}

Although surgical aortic valvotomy, transventricular without cardiopulmonary bypass (CPB) or open valvotomy with CPB, was previously perceived as extremely high risk with significant morbidity and mortality, it is now considered to be relatively safe and effective. ${ }^{(32)}$

Absolute indications for surgical management include the need for a single ventricle repair and the presence of additional defects that can only be addressed surgically e.g. small aortic annulus, sub- or

TABLE I: Outcome related to morphology. ${ }^{(8)}$

\begin{tabular}{|c|c|c|c|c|c|c|}
\hline Morphology & Al & Re-BAV & AVR & $\begin{array}{c}\text { Death I } \\
\text { TP }\end{array}$ & $\begin{array}{l}\text { Any } \\
\text { event }\end{array}$ & TOTAL \\
\hline $\begin{array}{l}\text { Functionally } \\
\text { Bicuspid }\end{array}$ & $24(26 \%)$ & $4(4 \%)^{*}$ & $7(8 \%)^{*}$ & $2(2 \%)^{*}$ & $13(14 \%)^{*}$ & 92 \\
\hline $\begin{array}{l}\text { True } \\
\text { Bicuspid }\end{array}$ & $6(46 \%)$ & I (8\%) & $6(46 \%)^{*}$ & I (8\%) & $7(5 \%)^{*}$ & 13 \\
\hline $\begin{array}{l}\text { Functionally } \\
\text { Unicuspid }\end{array}$ & $8(40 \%)$ & $7(35 \%)^{*}$ & $6(30 \%)^{*}$ & I (5\%) & $10(50 \%)^{*}$ & 20 \\
\hline $\begin{array}{l}\text { True } \\
\text { Unicuspid }\end{array}$ & $2(33 \%)$ & $2(33 \%)$ & 0 & $3(50 \%)^{*}$ & $4(67 \%)^{*}$ & 6 \\
\hline Dysplastic & $4(25 \%)$ & $5(31 \%)^{*}$ & $2(13 \%)$ & $3(19 \%)$ & $6(38 \%)$ & 16 \\
\hline TOTAL & $\begin{array}{l}44 / 147 \\
(30 \%)\end{array}$ & $\begin{array}{r}19 / 147 \\
(13 \%)\end{array}$ & $\begin{array}{r}21 / 147 \\
(14 \%)\end{array}$ & $\begin{array}{c}10 / 147 \\
(7 \%)\end{array}$ & $\begin{array}{r}40 / 147 \\
(27 \%)\end{array}$ & 147 \\
\hline
\end{tabular}

* Statistically significantly different as compared to the total group, $P$ value $<0.05$.

\section{TABLE 2: Surgical Aortic Valvotomy (Literature review). ${ }^{(20)}$}

\begin{tabular}{|c|c|c|c|c|c|c|}
\hline Reference & Year & Patients & $\begin{array}{l}\text { Age } \\
\text { (Mean) }\end{array}$ & $\begin{array}{l}\text { Time } \\
\text { interval } \\
(y)\end{array}$ & $\begin{array}{l}\text { Mortality } \\
\text { overall }\end{array}$ & $\begin{array}{l}\text { Re-do } \\
\text { pro- } \\
\text { cedure }\end{array}$ \\
\hline Justo(36) & 1996 & 90 & n/a & 3.6 & $15(17 \%)$ & $44 \%$ \\
\hline Chartrand $^{(25)}$ & 1999 & 67 & 8.8 & 10.6 & $3(5 \%)$ & $24 \%$ \\
\hline Lambert ${ }^{(37)}$ & 2000 & 121 & 2.4 & 9,4 & $15(21 \%)$ & $50 \%$ \\
\hline Detter ${ }^{(26)}$ & 2001 & 116 & 13.7 & 23.8 & $25 \%$ & $32 \%$ \\
\hline Bogers ${ }^{(56)}$ & 2001 & 11 & 2.7 & 4.8 & I(19\%) & $36 \%$ \\
\hline Alexiou ${ }^{(28)}$ & 2001 & 44 & 6.8 & 10.0 & 0 & $18 \%$ \\
\hline Tweddel(52) & 2005 & 47 & 9.9 & n/a & 0 & $13 \%$ \\
\hline Brown ${ }^{(20)}$ & 2012 & 89 & 7.1 & 9.8 & $2(5)$ & $43 \%$ \\
\hline TOTAL & & 566 & & 10.3 & $\begin{array}{c}12 \% \\
(3-25)\end{array}$ & $\begin{array}{c}34 \% \\
(13-50)\end{array}$ \\
\hline
\end{tabular}

supra-valvar aortic stenosis, coarctation, etc. The infant is thus assessed for suitability for a biventricular circulation using various protocols and scoring systems based variously on mitral valve diameter, indexed aortic root diameter, indexed MV area, indexed LV mass, LV inflow structures, morphology of the LVOT, length of the LV, presence and degree of EFE, and functional variables such as reversed flow in the ascending aorta and LV function. ${ }^{(33,34)}$ None of these scoring systems have proven to be completely accurate.

Predominantly reversed flow in the ascending aorta, particularly associated with decreased LV function, is ominous and a single ventricle repair (palliation) should be considered. In contrast, predominantly prograde flow in the ascending aorta and transverse arch correlates well with survival after a biventricular repair.(27) A small mitral valve orifice is a well-known risk factor for death. ${ }^{(26,30)}$ Therefore, if the mitral valve annulus diameter is less than $7 \mathrm{~mm}$ (or less than the $-2 \mathrm{z}$-score), or if there is severe LV inflow obstruction, one should consider a single ventricle palliation, and eventually attempt to promote growth if the rest of the LV is well developed. In addition, hypoplasia of the aortic annulus $(<5 \mathrm{~mm})$, a ratio of left to right ventricular lengths of $<0.8$, a cardiac apex not formed by the LV, and the presence of endocardial fibroelastosis (EFE) are contra-indications for SV (and BV). ${ }^{(25,26)}$ However, if some of these variables are correctable and biventricular repair is still feasible, the Ross/Ross-Konno operation is an option when the child is older. ${ }^{(25,28)}$

TABLE 3: Balloon Valvuloplasty (Literature review). ${ }^{20}$

\begin{tabular}{|c|c|c|c|c|c|c|}
\hline Reference & Year & Patients & $\begin{array}{c}\text { Age } \\
\text { (Mean) }\end{array}$ & $\begin{array}{c}\text { Time } \\
\text { interval } \\
(y)\end{array}$ & $\begin{array}{l}\text { Mortality } \\
\text { overall }\end{array}$ & $\begin{array}{l}\text { Re-do } \\
\text { pro- } \\
\text { cedure }\end{array}$ \\
\hline Justo(36) & 1996 & 107 & 5.7 & 3.1 & $2 \%$ & $\begin{array}{c}27 \% \\
(28 / 105)\end{array}$ \\
\hline Borghi ${ }^{(38)}$ & 1999 & 90 & 13.7 & 5.1 & $16 \%$ & $\begin{array}{c}48 \% \\
(39 / 81)\end{array}$ \\
\hline Jindal(57) & 2000 & 74 & $n / a$ & 5.5 & $0 \%$ & $\begin{array}{c}14 \% \\
(10 / 74)\end{array}$ \\
\hline Balmer ${ }^{(51)}$ & 2004 & 70 & 2.2 & 1.7 & $9 \%$ & $\begin{array}{c}35 \% \\
(24 / 68)\end{array}$ \\
\hline Reich $^{(58)}$ & 2004 & 269 & $n / a$ & 5.3 & $10 \%$ & $\begin{array}{c}29 \% \\
(78 / 269)\end{array}$ \\
\hline Brown $n^{(44)}$ & 2010 & 509 & 2.4 & 9.3 & $9 \%$ & $\begin{array}{c}44 \% \\
(225 / 509)\end{array}$ \\
\hline Brown ${ }^{(20)}$ & 2011 & 69 & 6.7 & 5.2 & $3 \%$ & $\begin{array}{c}47 \% \\
(32 / 68)\end{array}$ \\
\hline \multirow[t]{2}{*}{ Total } & & 1188 & & 5 & $7 \%$ & $35 \%$ \\
\hline & & & & & $\begin{array}{c}\text { (range } \\
0 \%-16 \%)\end{array}$ & $\begin{array}{l}\text { (range } \\
\text { 14\%-48\%) }\end{array}$ \\
\hline
\end{tabular}


A relative indication for surgery is a very bulky and dysplastic aortic valve. These valves have no clear leaflets or commissures and are fibrous and firm. BV, even with high pressure non-compliant balloons, often yields unsatisfactory results. ${ }^{(18)} \mathrm{SV}$ has the added benefit of visual identification of the commissures, if present, making precise surgical division possible. In addition any thick leaflet nodules can be shaved off and the leaflets thinned, giving better mobility of the leaflets during systole and coaptation during diastole. ${ }^{(17)}$ Interleaflet triangles and even neocommisures may be created. ${ }^{(35)}$

Several large studies have been published about the longterm follow up of neonates and infants that underwent SV for severe or critical AS. Alexiou, et al. published their data from 18 consecutively enrolled neonates who had open commissurotomies for critical AS. ${ }^{(28)}$ There were no operative deaths and the mean gradient at discharge was $<40 \mathrm{mmHg}$. Six infants had mild and 2 had moderate Al. Kaplan-Meier 5- and 10-year freedoms from any aortic re-operation or re-intervention were $85 \%$ and $55 \%$, respectively; 5- and 10-year freedoms from aortic valve replacement were 100\% and 79\%, respectively. Kaplan-Meier 10-year survival was 100\%. All their patients are leading normal lives and are in New York Heart Association class I. They conclude that SV for critical aortic stenosis in neonates has little risk and yields good freedom from recurrent AS or Al. The study published by Detter, et al., although based on the follow up over 3 decades of 67 slightly older children, showed that congenital AS in children can be controlled surgically until adulthood.(26)

\section{BALLOON VALVULOPLASTY (BV)}

In neonates, the aim of BV is to adequately relieve the LVOTO without causing significant $\mathrm{Al}$, and restoring normal LV function. As cardiac catheterisation techniques and equipment have improved, percutaneous balloon valvuloplasty can now be safely performed with little mortality and minimal morbidity and has become the intervention of choice in most centres for severe congenital AS. ${ }^{(38)}$

Neonates with critical AS on alprostadil should be kept sedated and intubated before the BV, to maintain haemodynamic stability during the procedure. In critically ill infants in whom the DA has closed, surgical and ECMO backup should be readily available.

Several methods of arterial accesses for aortic BV have been described over the last 2 decades, although no consensus has been reached as to which is optimal in the neonate. These include retrograde approaches via the femoral artery, the right subscapular artery, the umbilical artery, or the right carotid artery, as well as the prograde transvenous approach through the atrial septum via the foramen ovale. . $^{(39,40,41)}$
The advantages of the subscapular, carotid or umbilical arterial approaches, as well as the transvenous approach, include sparing of the femoral arteries for later re-intervention and reduced risk of femoral artery spasm or occlusion. This still occurs despite the use of very low profile balloon catheters (sheaths as small as $3 \mathrm{~F}$ are now available for use in neonates). The disadvantages include the small size of these vessels as well as the often-winding route via the umbilical artery. The transvenous prograde approach can also be challenging if the LV is small or hypertrophied. Care must be taken not to damage the mitral valve apparatus.

$\mathrm{BV}$ of the aortic valve via the right carotid artery is technically easy, although a surgical cut-down and repair of the vessel is usually required. This procedure has been described in the ICU under transesophageal echocardiographic (TEE) guidance, if neonatal size probes are available. This offers the advantages of continuous haemodynamic monitoring, continuous assessment for $\mathrm{Al}$, no exposure to fluoroscopy and no need to transport a sick neonate to and from the catheterisation laboratory. ${ }^{(42)}$

Great care must be taken during BV to avoid over-zealous dilation that would result in damage to the aortic valve and subsequent Al. ${ }^{(43)} \mathrm{BV}$ produces a tear at the weakest part of the aortic valve, which is often not at the fused commissures. Al may result from commissural avulsion, cusp dehiscence, cusp tears or perforation. Brown et al. found that a lower post-dilation AS gradient and less post-dilation Al led to longer freedom from aortic valve replacement (AVR). ${ }^{(44)}$ The difficulty faced in the catheterisation laboratory is usually the decision as to when to upsize (or not) the balloon, especially in patients with moderate residual gradients of 30 to $40 \mathrm{mmHg}$. Increasing the balloon size may lead to a lower residual gradient and therefore longer freedom from AVR. However, this may also result in an increased amount of Al which would cancel out the above benefit. ${ }^{(45)} \mathrm{A}$ balloon diameter to aortic valve annulus diameter ratio of $0.9: 1$ is recommended and should not be exceeded.

Maskatia, et al. reported their 25 year experience with $\mathrm{BV}$ for congenital aortic stenosis.(46) A retrospective single-institution review was performed and the following end points were evaluated: moderate or severe aortic insufficiency (Al) on echo, AVR, re-do BV, SV, transplantation or death. From 1985 to 2009, 272 patients who underwent BAV at ages I day to 30.5 years were followed for $5.8 \pm 6.7$ years. Transplantation or death occurred in 24 patients (9\%) and was associated with depressed LV function. Forty-two patients (I5\%) needed AVR at a median of 3.5 years; this was associated with residual $A S \geq 25 \mathrm{mmHg}(p=0.02)$, post-BAV AI 
$(p=0.03)$, and depressed LV function $(p=0.04)$. Al was found in 83 patients $(3 \mid \%)$ and was inversely related to post-BV gradient $\geq 25 \mathrm{mmHg}$ and was associated with depressed baseline LV function. Neonates, patients with post-BV gradients $\geq 25 \mathrm{mmHg}$, and patients with lower baseline LV function experienced worse outcomes.

Brown, et al. followed up 509 patients with a cumulative follow-up of 5003 patient years. Although peak AS gradients decreased well after dilation, I4\% of patients had moderate or severe Al. Survival free from aortic valve re-intervention was $1 \%$ at I year, $2 \%$ at 5 years, 3\% at 10 years, and 3\% at 20 years. Freedom from AVR was $2 \%$ at 5 years, $3 \%$ at 10 years, and $4 \%$ at 20 years. After multivariate analyses, lower post-dilation AS gradient grade of $\mathrm{Al}$ were associated with longer freedom from AVR, but age and predilation AS severity were not. They conclude that although $B V$ is effective for relief of congenital AS, there are steady long-term hazards for surgical re-intervention and replacement. ${ }^{(42)}$

The amount of residual aortic stenosis or incompetence after SV or BV is an important predictor of the infant's long-term outcome and significantly affects the quality of life. ${ }^{(47)}$ Neonates undergoing SV are more likely to have residual stenosis, particularly in unicuspid or bicuspid valves. This residual AS can however, have a positive effect on the growth of the LV and the annulus of the aortic valve. ${ }^{(48)}$ Conversely, $\mathrm{Al}$ is more common after $\mathrm{BV} .{ }^{(49)}$ McElhinney, et al. found that infants with post-BV Al had a more rapid increase in LVED z-scores at follow-up. ${ }^{(50)}$ Even mild residual $\mathrm{Al}$ is a risk factor for progressive $\mathrm{Al}$ and ventricular dysfunction and may require earlier $A \bigvee R .{ }^{(31,51)}$

\section{AORTICVALVE REPLACEMENT (AVR)}

The majority of patients with severe AS will need further surgery after either BV or SV. This may take the form of eventual aortic valve repair, replacement or even cardiac transplantation. The presence of severe residual stenosis or incompetence after BV and/ or SV, LV dilation and decrease in LV function are indications for AVR. This is put off as long as possible in small children with small aortic annuli, whilst closely monitoring LV function. This ensures a better patient-valve match for increased valve longevity and interval between re-do replacements.

The 3 options for eventual AVR are: mechanical prosthetic valves, bioprosthetic valves and the Ross procedure. Recently a fourth option has become available, namely transcutaneous aortic valve implantation (TAVI). The management of anticoagulation (in pregnancy and other), teratogenic effects of warfarin, anticipated need for re-operation or re-intervention, etc. should be extensively discussed with the patient and family beforehand.

Mechanical prosthetic valves are long lasting but require lifelong anticoagulation. If implanted too early, they have a greater potential for early development of patient-prosthesis mismatch.

The bioprosthetic valves (bovine, porcine, and cadaver homografts) do not need anticoagulation but are less durable. They may be considered in patients with contra-indications to mechanical valves and anticoagulation.

The Ross procedure is an auto-transplantation of the pulmonary valve to the aortic position, with the insertion of a pulmonary homograft in the pulmonary position. It allows growth of native tissue and avoids the need for anticoagulation and many sport restrictions. Unfortunately, children tend to develop early calcific stenosis and/or insufficiency of the pulmonary homograft. This can lead to repeated interventional catheterisations or surgical reoperations to relieve the RVOTO. Percutaneous pulmonary valve implantation (PPVI) is now available for older children and adults and can reduce the need for multiple surgical pulmonary conduit replacements.

TAVI is currently not an option for small children as the delivery system is too large. Longterm follow-up data is also limited.

Some units advocate aortic valve repair rather than replacement. The advantages of valve repair obviously include increased potential for growth, preservation of the pulmonary valve as a later option for the Ross procedure, lack of anticoagulation and delay of AVR. The disadvantages include significant residual stenosis or insufficiency.

Tweddell, et al. demonstrated that complex aortic valve repair achieves intermediate outcomes similar to those of aortic valve replacement (see Table 4). ${ }^{(52)}$ They suggest further studies to determine long-term outcomes and to better identify candidates for valve repair. At present valve repair is considered for patients with an adequate aortic annulus, without extensive leaflet destruction, and with the potential for a satisfactory result with a minimum of prosthetic material.

\section{UNIVENTRICULAR REPAIR}

Infants with anatomy precluding a biventricular repair or with severe LV dysfunction may be palliated with a staged univentricular approach such as the Norwood procedure. Stage I involves anastomosis of the pulmonary artery to the aortic arch to increase 


\begin{tabular}{|l|c|c|c|}
\hline $\begin{array}{l}\text { TABLE 4: Results of complex aortic valve repair versus valve } \\
\text { replacement. }\end{array}$ (52) \\
\hline & Repair & AVR & p-value \\
\hline No. & 57 & 57 & \\
\hline Age at operation & $9.4 \pm 7.9$ & $12.4 \pm 8.3$ & .049 \\
\hline Previous intervention & $25 \%$ & $37 \%$ & .20 \\
\hline Indication: AS & $35 \%$ & $16 \%$ & \\
\hline Al & $32 \%$ & $42 \%$ & \\
\hline AS and Al & $33 \%$ & $42 \%$ & \\
\hline Residual gradient & $20 \pm 21$ & $12.5 \pm 25$ & .10 \\
\hline Al mild or less & $67 \%$ & $84 \%$ & .07 \\
\hline Al moderate or less & $94 \%$ & $92 \%$ & .72 \\
\hline
\end{tabular}

systemic outflow, placement of either a systemic-to-pulmonary arterial shunt or RV to PA conduit to provide pulmonary blood flow, and atrial septectomy to ensure unobstructed pulmonary venous return. Stage 2 is a bidirectional Glenn with anastomosis of the superior vena cava to the pulmonary arteries. Stage 3 is the Fontan completion with conduit anastamosis of the IVC to the pulmonary arteries. The overall survival with the Norwood repair varies according to institution. More than $50 \%$ of survivors have neurodevelopmental impairment. ${ }^{(53)}$

\section{CONCLUSION}

The management of severe or critical AS in the neonate is challenging. Recent editorials written by Neil Wilson and Carl Backer conclude that there is still no clear-cut treatment of choice. ${ }^{(54,55)}$ The decision whether to opt for surgical or balloon valvuloplasty must be guided by the morphology of each individual aortic valve. All treatment modalities have their advantages and disadvantages with a current slant towards open surgical valvotomy. ${ }^{(33)}$ Re-interventions and re-operations are inevitable and expected, but if managed carefully, aortic valve replacement can be avoided or delayed until the implantation of an adult-sized prosthesis is possible.

\section{Conflict of interest: none declared.}

\section{REFERENCES}

I. Botto LD, Correa A, Erickson JD. Racial and temporal variations in the prevalence of heart defects. Paediatrics 200 I;107(3):E32.

2. Hoffman Jl, Kaplan S. The incidence of congenital heart disease. J Am Coll Cardiol 2002;39(12): 1890-1900

3. Wagner HR, Ellison RC, Keane JF, et al. Clinical course in aortic stenosis. Circulation 1977; 56(I Supp):147-56

4. Garg V, Muth AN, Ransom JF, et al. Mutations in NOTCHI cause aortic valve disease. Nature 2005;437(7056):270-274.

5. Tennstedt C, Chaoui R, Körner H, et al. Spectrum of congenital heart defects and extracardiac malformations associated with chromosomal abnormalities: Results of a 7 year necropsy study. Heart 1999:82(1):34-9.

6. Anderson RH, Webb S, Brown NA, et al. Development of the heart: Three formation of the ventricular outflow tracts, arterial valves, and intrapericardial arterial trunks. Heart Sep 2003;89(9): I I I0-8.

7. Restivo A, Piacentini G, Placidi S, et al. Cardiac outflow tract: A review of some embryogenetic aspects of the conotruncal region of the heart. Anat Rec A Discov Mol Cell Evol Biol 2006;288(9):936-43.

8. Maskatia SA, Justino $\mathrm{H}$, Ing FF, et al. Aortic valve morphology is associated with outcomes following balloon valvuloplasty for congenital aortic stenosis Catheterisation and Cardiovasc Interv. 2013;8I ( I):90-95.

9. Evangelista A. Bicuspid Aortic Valve and Aortic Root Disease. Cur Cardiol Rep 201 1;13(3):234-241.

10. Siu SC, Silversides CK. Bicuspid Aortic Valve Disease. J Am Coll Cardiol 20I0; 55(25):2789-2800.

I1. Davies MJ. Pathology of Cardiac Valves. London: Butterworths \& Co; |980. 51-61.

12. Brandenburg RO, Tajik AJ, Edwards WD, et al. Accuracy of 2-dimensional echocardiographic diagnosis of congenitally bicuspid aortic valve: Echocardiographic-anatomic correlation in I I5 patients. Am J Cardiol 1983;51:1469-1473.

13. Beroukhim RS, Kruzick TL, Taylor AL, et al. Progression of aortic dilation in children with a functionally normal bicuspid aortic valve. Am J Cardiol 2006; 98:828-830.

14. Michelena HI, Khanna AD, Mahoney D, et al. Incidence of Aortic Complications in Patients with Bicuspid Aortic Valves. J Am Med Assoc 20 I 1;306 ( I0): I I 04- I I 12.

15. Aldo C, Russo CF, Vitali E. Bicuspid Aortic Valve: About Natural History of Ascending Aorta Aneurysms. Ann Thorac Surg 2008;85( ( ):362-363.

16. Sood N, Taub C. Unicuspid Aortic Valve: An Interesting Presentation. Eur Heart J 2008;29(10): 1295.

17. Mookadam F, Thota V, et al. Unicuspid aortic valve in children. J Heart Valve Dis 2010;19(6):678-683.

18. Brock M, Tugertimur A, Schwartz MC. A rare paediatric cardiac anomaly: Quadricuspid aortic valve with Aortic regurgitation. Ann Pediatr Card 20I3;6:202-3.

19. Di Pino A, Gitto P, Silvia A, et al. Congenital quadricuspid aortic valve in children. Cardiology in the young 2008;18(3):324-327.

20. Brown JW, Rodefeld MD, Ruzmetov M, et al. Surgical valvuloplasty versus balIoon aortic dilation for congenital aortic stenosis: Are evidence-based outcomes relevant? Ann Thorac Surg 2012;94:146-55

21. Weber H. Paediatric Valvar Aortic Stenosis. eMedicine 2013 Oct.

22. Lofland GK, McGrindle BW, Williams WG, et al. Critical aortic stenosis in the neonate: A multi-institutional study of management, outcomes, and risk factors. J Thorac Cardiovasc Surg 2001;121:10-27.

23. Hickey EJ, Caldarone CA, Blackstone EH, et al. Critical left ventricular outflow tract obstruction: The disproportionate impact of biventricular repair in borderline cases. J Thorac Cardiovasc Surg 2007; 1 34:1429-37.

24. Kovalchin JP, Brook MM, Rosenthal GL, et al. Echocardiographic haemodynamic and morphometric predictors of survival after two-ventricle repair in infants with critical aortic stenosis. J Am Coll Cardiol 1998;32:237-4. 
25. Chartrand CC, Saro-Servando E, Vobecky JS. Long-term results of surgical valvuloplasty for congenital valvar aortic stenosis in children. Ann Thorac Surg 1999;68: 1356-60.

26. Detter $C$, Fischlein $T$, Feldmeier $C$, et al. Aortic valvotomy for congenital valvular aortic stenosis: A 37-year experience. Ann Thorac Surg 200 I;71:1564-71.

27. Karl TR, Sano S, Brawn WJ, et al. Critical aortic stenosis in the first month of life: Surgical results in 26 infants. Ann Thorac Surg 1990;50:105-9.

28. Alexiou C, Langley SM, Dalrymple-Hay, et al. Open commissurotomy for critical isolated aortic stenosis in neonates. Ann Thorac Surg 200।;489-93.

29. Pan XB, Zhang $\mathrm{H}$, Hu SS, et al. Efficacy of hybrid balloon valvuloplasty via sternotomy for treating low-body weight infants with severe congenital valvular aortic stenosis. Zhonghua Xin Xue Guan Bing Za Zhi 20I2;40(8):68I-3.

30. Maschiettom N, Vidam $\vee$, Milanes $O$. Transapical aortic balloon valvuloplasty in an 890 gram infant: Hybrid is better! Catheterisation and Cardiovasc Interv. 2011;77:112-114.

31. Kang D, Park S, Rim J, et al. Early surgery versus conventional treatment in asymptomatic very severe aortic stenosis. Circulation 2010;121:1502-1509.

32. Hraška $\vee$, Sinzobahamvya N, Haun C, et al. The Long-term outcome of open valvotomy for critical aortic stenosis in neonates. Ann Thorac Surg 2012;94: 1519-26.

33. Eicken A, Georgiev S, Balling G, et al. Neonatal balloon aortic valvuloplasty-predictive value of current risk score algorithms for treatment strategies. Catheter Cardiovasc Interv 2010;76(3):404-10.

34. Colan SD, McElhinney D, Crawford EC, et al. Validation and re-evaluation of a discriminant model predicting anatomic suitability for biventricular repair in neonates with aortic stenosis. J Am Coll Cardiol 2006;47: 1858-65.

35. Siddiqui J, Brizard C, Galati JC, et al. Surgical valvotomy and repair for neonatal and infant congenital aortic stenosis achieves better results than interventional catheterisation. JACC 2013;62(22):2134-40

36. Justo RN, McCrindle BW, Benson LN, et al. Aortic valve regurgitation versus percutaneous balloon valvotomy for congenital aortic valve stenosis. Am J Cardiol 1996; 15:1332-8.

37. Lambert V, Obreja D, Losay J, et al. Long-term results after valvotomy for congenital aortic valvar stenosis in children. Cardiol Young 2000; 10(6):590-6.

38. Borghi A, Agnoletti $G$, Valsecchi $O$, et al. Aortic balloon dilatation for congenital stenosis: Report of 90 cases (1986-98). Heart 1999;82(6);el0.

39. Magee AG, Nykanen D, McCrindle BW, et al. Balloon dilation of severe aortic stenosis in the neonate: comparison of anterograde and retrograde catheter approaches. J Am Coll Cardiol. 1997;30(4): 1061-6.

40. Alekyan BG, Petrosyan YS, Coulson JD, et al. Right subscapular artery catheterisation for balloon valvuloplasty of critical aortic stenosis in infants. Am J Cardiol 1995;76(14): 1049-52.

41. Fischer DR, Ettedgui JA, Park SC, et al. Carotid artery approach for balloon dilation of aortic valve stenosis in the neonate: A preliminary report. J Am Coll Cardiol 1990; 15(7): 1633-6.

42. Weber HS, Mart CR, Myers JL. Transcarotid balloon valvuloplasty for critical aortic valve stenosis at the bedside via continuous transesophageal echocardiographic guidance. Catheter Cardiovasc Interv 2000;50(3):326-9.

43. Hamidi-Manesh L, Tibby SM, Herman R, et al. Influence of balloon size on aortic regurgitation in neonates undergoing balloon aortic valvuloplasty: A retrospective study over an II-year period. J Interven Cardiol 20 I3;26:200-207.

44. Brown DW, Dipilato $A E$, Chong EC, et al. Aortic valve re-interventions after balloon aortic valvuloplasty for congenital aortic stenosis: intermediate and late follow-up. J Am Coll Cardiol 2010;56:1740-9.

45. Holzer R, Cheatham J. Shifting the balance between aortic insufficiency and residual gradients after balloon aortic valvuloplasty. JACC 20 I0;56(21): 1750-I.
46. Maskatia SA, Ing FF, Justino $\mathrm{H}$, et al. Twenty-five year experience with balloon aortic valvuloplasty for congenital aortic stenosis. Am J Cardiol 201। Oct I; 108(7): 1024-8.

47. Karamlou T, Shen I, Alsoufia B, et al. The influence of valve physiology on outcome following aortic valvotomy for congenital bicuspid valve in children: Thirty-year results from a single institution. Eur J Cardiothorac Surg 2005;27:81-5.

48. Han RK, Gurofsky RC, Lee KJ, et al. Outcome and growth potential of left heart structures after neonatal intervention for aortic valve stenosis. J Am Coll Cardiol 2007;50:25.

49. McCrindle BW, Blackstone EH, Williams WG, et al. Are outcomes of surgical versus transcatheter balloon valvotomy equivalent in neonatal critical aortic stenosis? Circulation 200 I; 104( I2 Suppl I):II 52-8.

50. McElhinney DB, Lock JE, Keane JF, et al. Left heart growth, function, and reintervention after balloon aortic valvuloplasty for neonatal aortic stenosis. Circulation 2005; 1 । 1:45 10-8.

5।. Balmer C, Beghetti M, Fasnacht M, et al. Balloon aortic valvoplasty in paediatric patients: Progressive aortic regurgitation is common. Heart 2004;90:77-81.

52. Tweddell JS, Pelech AN, Jaquiss RDB, et al. Aortic valve repair. Semin Thorac Cardiovasc Surg Paediatr Card Surg Annu 2005;8:1 12-21.

53. Ashburn DA, McCrindle BW, Tchervenkov Cl, et al. Outcomes after the Norwood operation in neonates with critical aortic stenosis or aortic valve atresia. J of Thorac and Cardiovasc Surg 2003; 125(5): 1070-82.

54. Wilson N. Aortic valve morphology is associated with outcomes following balloon valvuloplasty for congenital aortic stenosis: Reflection on morphological retrospection aids selection for interventional rejection. Catheterisation and Cardiovasc Interv. 2013;81 (1):96.

55. Backer C. Infant congenital aortic stenosis: The Pendulum Swings JACC 2013; 62(22):214|-43.

56. Bogers AJ, Takkenberg J), Kappetein AP, et al. Is there a place for paediatric valvotomy in the autograft era? Eur J Cardiothorac Surg 200 I;20(1):89-94.

57. Jindal RC, Saxena A, Juneja R, et al. Long-term results of balloon aortic valvulotomy for congenital aortic stenosis in children and adolescents. J Heart Valve Dis 2000;9:623-8.

58. Reich $\mathrm{O}, \mathrm{Tax}$ P, Marek J, et al. Long term results of percutaneous balloon valvuloplasty of congenital aortic stenosis: Independent predictors of outcome. Heart 2004;90:70-6. 